Review

\title{
From Target-Oriented to Motif-Oriented: A Case Study on Nannocystin Total Synthesis
}

\author{
Weicheng Zhang(1) \\ The State Key Laboratory of Medicinal Chemical Biology, College of Pharmacy, and Tianjin Key Laboratory of \\ Molecular Drug Research, Nankai University, Tianjin 300353, China; zhangweicheng@nankai.edu.cn \\ Academic Editor: David Díez \\ Received: 27 October 2020; Accepted: 11 November 2020; Published: 15 November 2020 \\ check for \\ updates
}

\begin{abstract}
Natural product total synthesis is in essence target-oriented in that a set of organic transformations are orchestrated into a workable process, leading ultimately to the target molecule with a predefined architecture. For a bioactive lead, proof of synthetic viability is merely the beginning. Ensuing effort repurposes the initial synthesis for structural diversification in order to probe structure-activity relationship (SAR). Yet accessibility is not equal to flexibility; moving from convergency to divergency, it is not always feasible to explore the chemical space around a particular substructure of interest simply by tweaking an established route. In this situation, the motif-oriented strategy becomes a superior choice, which gives priority to synthetic flexibility at the concerned site such that a route is adopted only if it is capable of implementing diversification therein. This strategy was recently devised by Fürstner et al., enabling them to achieve total synthesis of both natural and non-natural nannocystins varied at an otherwise challenging position. The present review examines seven distinctive nannocystin total syntheses reported thus far and showcases the merits of conventional (target-oriented) as well as motif-oriented strategies, concluding that these two approaches complement each other and are both indispensable for natural product based drug discovery.
\end{abstract}

Keywords: total synthesis; motif-oriented; nannocystin; macrocyclization

\section{Introduction}

Nannocystin A (1, Figure 1) and its natural congener nannocystin Ax (2) are myxobacterial secondary metabolites with excellent anticancer potency, which target eukaryotic elongation factor 1A (eEF1A) [1,2]. Structurally, 1 features a rigid 21-membered macrocycle adorned with nine chiral centers, two conjugated $E$-alkenes, as well as an $N$-methyl $\alpha, \beta$-epoxy amide. Its strong antiproliferative activity, novel macrocyclic architecture, and distinct mode of action spurred endeavors from several labs to explore total synthesis. Apart from addressing the supply issue, synthetic access to 1 empowers more freedom of structural modification than biotechnological (fermentation) process. On behalf of drug discovery, it is not just a prerequisite for SAR study, but a vital way to fine-tune the many physicochemical properties of a natural lead during preclinical development. Thus far seven total syntheses of 1 or 2 have been accomplished [3-9], with a short summary appearing recently [10]. For efficient macrocycle generation, all synthetic routes embody the principle of convergency. Namely, synchronous preparation of a few discrete fragments precedes their sequential incorporation into a linear precursor suited for a final macrocyclization. Making a good case for the versatility and flexibility of organic synthesis, each approach deploys a unique reaction type and/or ring closure site to forge the 21-membered ring (methods A-G, Figure 2), as will be detailed below. 


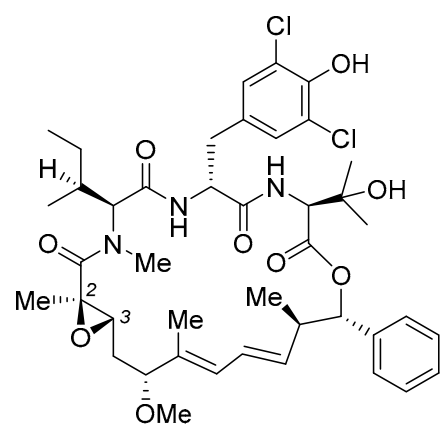

nannocystin $A(1)$

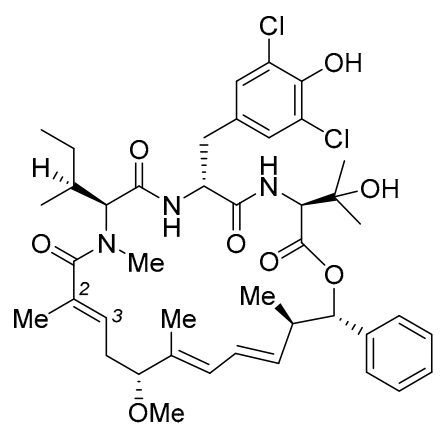

nannocystin $A x(2)$

Figure 1. Structures of nannocystin A (1) and nannocystin Ax (2).

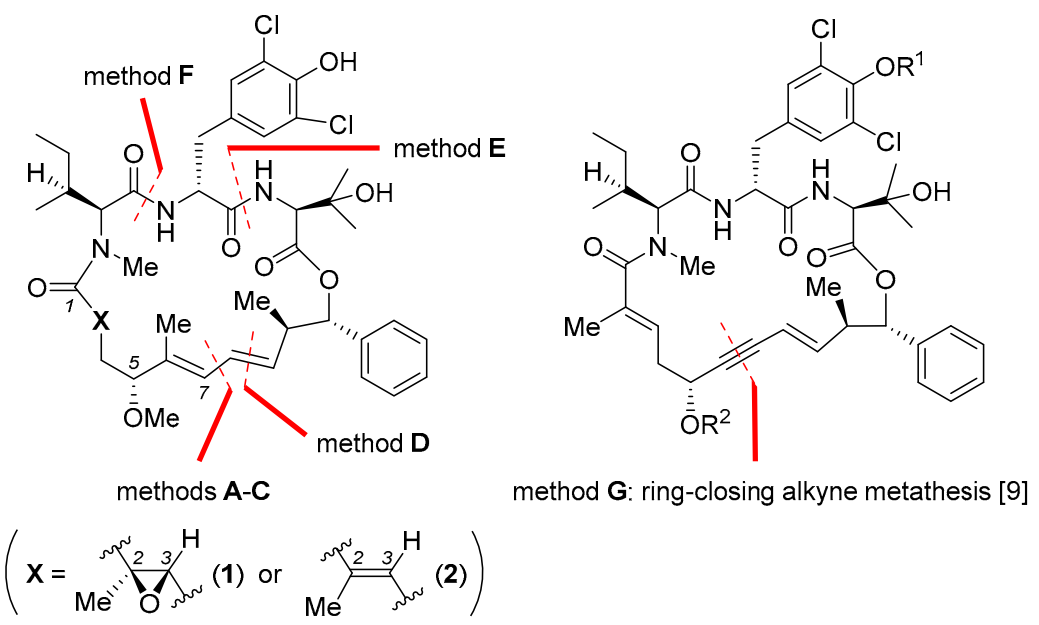

method A: Suzuki cross-coupling [3]

method B: Heck cross-coupling [5]

method C: Stille cross-coupling [6]

method D: ring-closing alkene metathesis [4]

method E: macrolactamization [7]

method F: macrolactamization [8]

Figure 2. Key macrocyclization reactions (methods $\mathbf{A}-\mathbf{G}$ ) employed for the total synthesis of $\mathbf{1}$ and/or 2 [3-9].

\section{Macrocyclization via Suzuki Cross-Coupling}

In 2016, $\mathrm{Xu}$ and $\mathrm{Ye}$ et al. reported total synthesis of $\mathbf{1}$ featuring macrocyclization via Suzuki cross-coupling (Figure 2, method A) [3]. In their retrosynthetic analysis, the final ring closure was planned to join the $\mathrm{C} 7$ and $\mathrm{C} 8$ termini of $\mathbf{2 0}$ (nannocystin numbering) in a stereodefined fashion. To access the open-chain precursor 20 , it is necessary to prepare three key building blocks $\mathbf{6 , 1 2}$, and $\mathbf{1 8}$ (boxed in Scheme 1) beforehand.

Starting with commercially available L-tyrosine derivative 3, a three-step protecting group manipulation (multistep reaction condition [A] at the bottom of Scheme 1) revealed the free amine of $\mathbf{4}$ for subsequent amide coupling with $N$-Boc- $N$-methyl-L-isoleucine 5. Boc deprotection gave dipeptide 6 as the first building block. Next, $\mathrm{TiCl}_{4}$-mediated vinylogous Mukaiyama aldol condensation [11-14] was implemented between a vinylketene silyl $\mathrm{N}, \mathrm{O}$-acetal derived from 7 and (E)-3-iodo-2-methylacrylaldehyde (8), affording chiral secondary alcohol 9 in $69 \%$ yield. Methylation of the nascent $5 R$ hydroxyl group, followed by reductive cleavage of the oxazolidinone auxiliary ([B]), gave rise to allylic alcohol 10. Then Sharpless asymmetric epoxidation came into play and furnished chiral epoxide $\mathbf{1 1}$ as a single stereoisomer. Such prepared chiral epoxy alcohol was further converted to the second key fragment 12 via stepwise oxidation ([C]). 

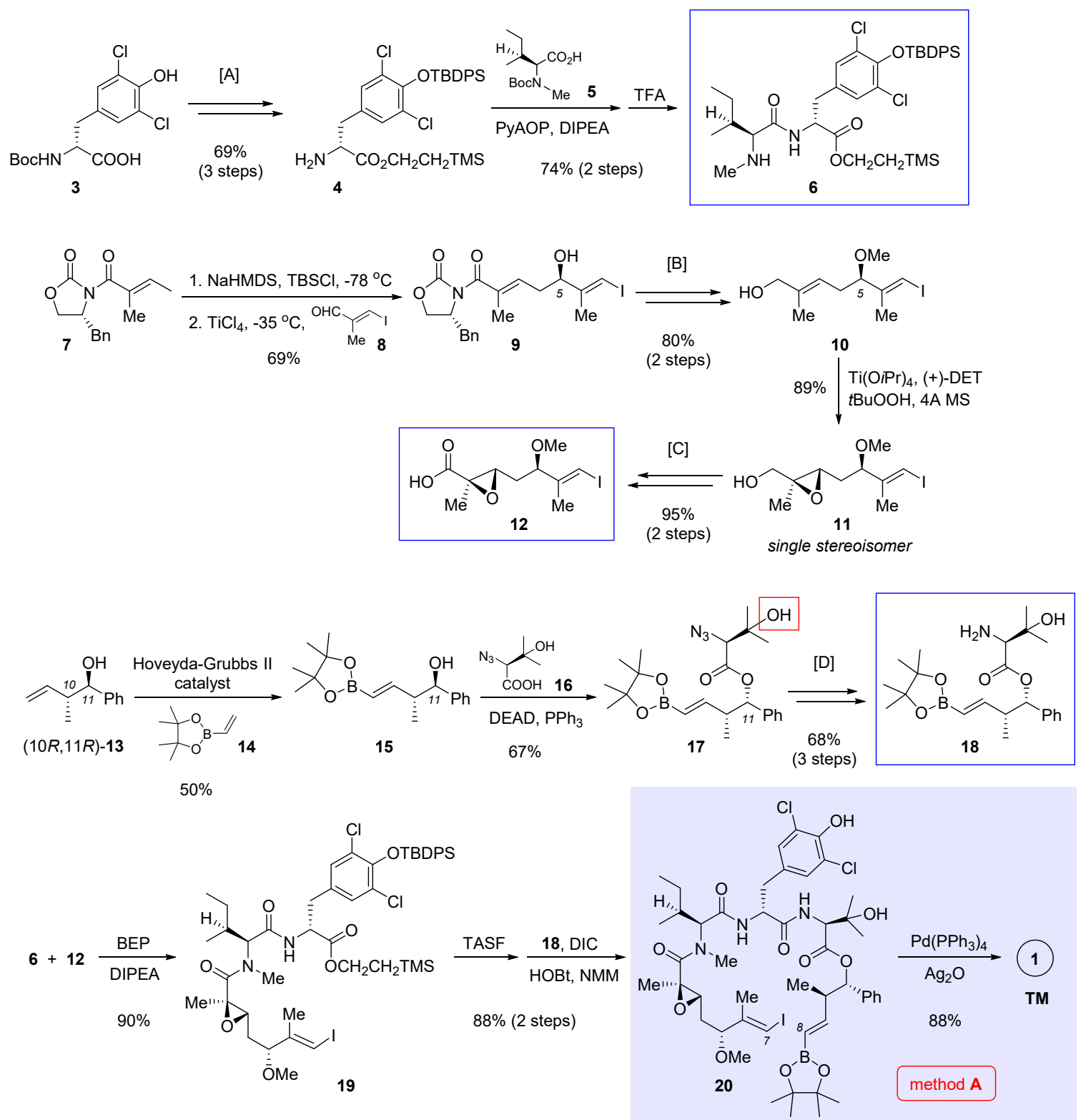

Multistep reaction conditions

[A] 1. TBDPSCl, imidazole;

2. $\mathrm{TMSCH}_{2} \mathrm{CH}_{2} \mathrm{OH}, \mathrm{DMAP}, \mathrm{EDC}$

(69\% for 2 steps);

3. TFA $(100 \%)$.

[B] 1. proton sponge, $\mathrm{Me}_{3} \mathrm{O}^{+} \mathrm{BF}_{4}^{-}$; 2. $\mathrm{LiBH}_{4}, 0{ }^{\circ} \mathrm{C}(80 \%$ for 2 steps $)$.
[C] 1. Dess-Martin periodinate, $\mathrm{NaHCO}_{3}$;

2. $\mathrm{NaClO}_{2}, \mathrm{NaH}_{2} \mathrm{PO}_{4}, 2$-methyl-2-butene, $0{ }^{\circ} \mathrm{C}$ (95\% for 2 steps).

[D] 1. TMSOTf, TEA; 2. $\mathrm{PMe}_{3}$;

3. $\mathrm{HCl}(68 \%$ for 3 steps).

Scheme 1. Total synthesis of $\mathbf{1}$ by $\mathrm{Xu}$ and Ye et al. featuring macrocyclization via Suzuki cross-coupling

(Figure 2, method A) [3].

Preparation of the third building block 18 was initiated by olefin cross-metathesis of the known homoallylic alcohol $(10 R, 11 R)-\mathbf{1 3}$ and pinacol boronate 14 with the help of Hoveyda-Grubbs II catalyst. The resulting 15 was united with 16 via Mitsunobu esterification whereby the $C 11$ chirality was inverted. In the next step, it seems surefire at first sight to obtain 18 directly through Staudinger reduction of the azide group present in 17; rather, the authors isolated an unwanted epoxide as the predominant product, presumably caused by the neighboring $\beta$-hydroxyl group (highlighted in 17). Therefore, this interfering group was masked ad hoc as a TMS ether prior to azide reduction. Acid hydrolysis of the TMS group led to $\mathbf{1 8}$ thereafter ([D]). 
With all three essential pieces in hand, they were linked up via two amidation reactions. The first coupling between 6 and $\mathbf{1 2}$ is nontrivial, as a variety of common condensation reagents such as EDCI, HATU and PyAOP failed to create the desired amide bond. Fortunately, 2-bromo-1-ethyl pyridinium tetrafluoroborate (BEP) turned out superior, bringing about the coupling product 19 in a satisfactory yield (90\%). Unmasking the carboxylic acid of 19 with TASF allowed the second amidation to deliver the penultimate intermediate 20. Finally, in the presence of $\mathrm{Pd}\left(\mathrm{PPh}_{3}\right)_{4}$ and $\mathrm{Ag}_{2} \mathrm{O}$, an intramolecular Suzuki cross-coupling closed the macrocycle, thereby attaining total synthesis of nannocystin A (Scheme 1).

\section{Macrocyclization via Heck Cross-Coupling}

Parallel to Xu and Ye's work, we independently achieved total synthesis of 1 [5]. Central to our approach is an intramolecular Heck cross-coupling to forge the strategic C7-C8 bond (Figure 2, method B). Owing to unfavorable entropy loss and competition from intermolecular reactions, macrocyclization is oftentimes among the most demanding steps in macrocycle synthesis. The rationale behind our retrosynthetic deconstruction is to exploit a less sterically congestive site. In this way, we anticipated the enthalpy barrier to overcome could be lowered during the macrocycle-forming process. According to the crystal structures of nannocystin A (1) [2] and its phenolic methyl ether [1], we felt the polyketide C7-C8 bond stitching two trans alkenes might be amenable to a Heck-type cyclization. Compared with alternative Pd-catalyzed cross-coupling reactions such as the Suzuki cross-coupling utilized in the preceding synthesis (method A, Scheme 1) [3], Heck reaction saves the need to preassemble a latent olefinic boronate handle, thus shortening the whole route. However, a patent concern implicated by this plan lies in the uncertainty of its stereochemical outcome. In other words, unless put into practice, it is difficult, if not impossible, to tell a priori whether the cyclized product would bear the desired $8 E$-alkene, or exist as a mixed $8 Z$ - and $8 E$-stereoisomers, or even worse, show up exclusively with the opposite $8 Z$ configuration.

Determined to explore the feasibility of this idea, we set out (Scheme 2) by preparing dipeptide 23 via amidation of tyrosine derivative 21 with 22 and subsequent cleavage of the Fmoc group. Meanwhile, chiral $\alpha, \beta$-epoxy carboxylic acid 12 (structure shown in Scheme 1) was synthesized in 6 steps, involving vinylogous Mukaiyama aldol condensation [11] and Sharpless asymmetric epoxidation to create three stereocenters (multistep reaction conditions [A] and [B] compiled at the right of Scheme 2). Entry to $\mathbf{2 7}$ was secured through Mitsunobu esterification of (10R,11R)-13 (structure in Scheme 1) with 25 followed by Boc deprotection. We also tried conventional ester condensation of the diastereomeric (10R,11S)-13 and 25, but the reaction was too sluggish to yield $\mathbf{2 6}$.

Having prepared all three necessary building blocks 23, 12, and 27, we advanced to the linear intermediate 29 by first joining 23 and 12 via amidation, and after ester hydrolysis, attaching another fragment 27 through a second amidation. To our relief, the final macrocyclization under Heck cross-coupling condition $\left(\mathrm{Pd}(\mathrm{OAc})_{2}, \mathrm{NEt}_{3}, \mathrm{Cs}_{2} \mathrm{CO}_{3}\right)$ proceeded well to afford the product in $58 \%$ yield as a configurationally pure $8 E$-nannocystin. No $8 Z$-isomer could be detected by NMR in the crude reaction mixture. Marked by a Heck-type macrocyclization, this route has since served a valuable conduit for systematic SAR research [15-18]. 

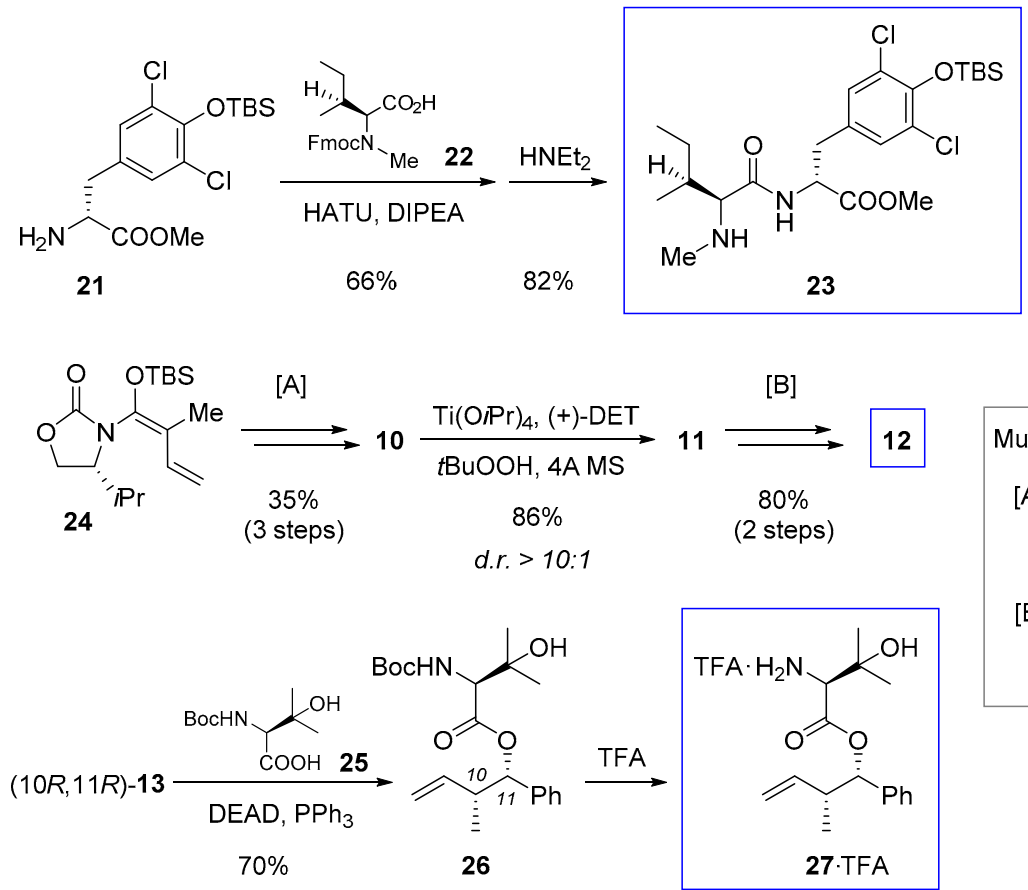

Multistep reaction conditions

[A] 1. $\mathrm{TiCl}_{4},-78^{\circ} \mathrm{C}, 8(51 \%)$;

2. proton sponge, $\mathrm{Me}_{3} \mathrm{O}^{+} \mathrm{BF}_{4}^{-}(72 \%)$;

3. $\mathrm{NaBH}_{4}(95 \%)$.

[B] 1. Dess-Martin periodinate (84\%) 2. $\mathrm{NaClO}_{2}, \mathrm{NaH}_{2} \mathrm{PO}_{4}, 2$-methyl-2 -butene (95\%)

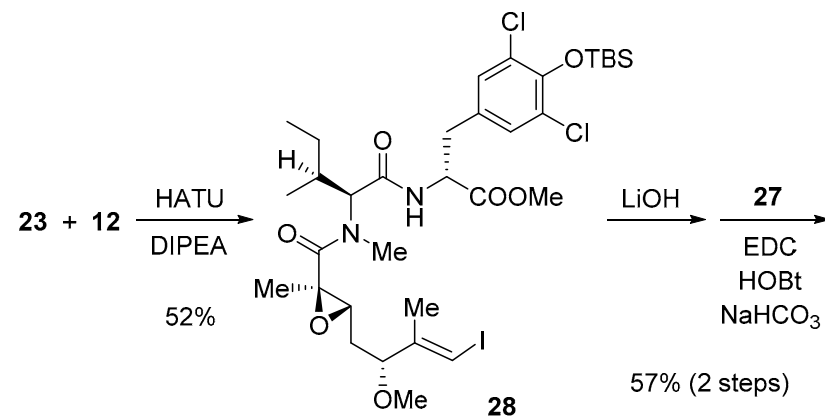

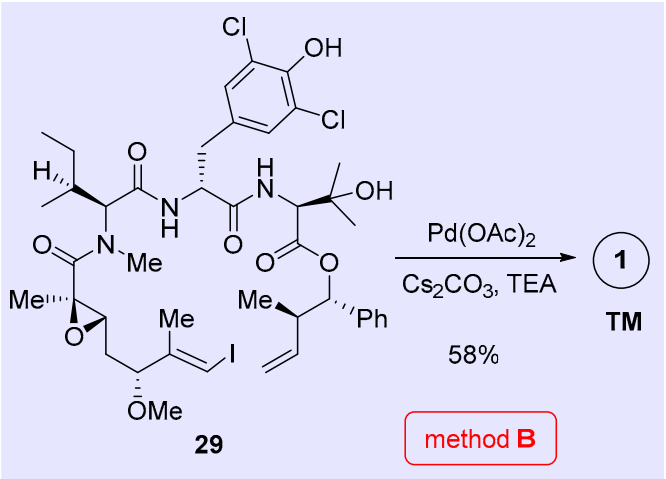

Scheme 2. Total synthesis of $\mathbf{1}$ by Zhang and Chen et al. featuring macrocyclization via Heck cross-coupling (Figure 2, method B) [5].

\section{Macrocyclization via Stille Cross-Coupling}

The value of Pd-catalyzed cross-coupling in macrocycle formation is further demonstrated in Liu's total synthesis of nannocystin Ax (2) [6], which relies on a Stille-type macrocyclization (Figure 2, method C). As is often the case with countless natural product syntheses [19], it is only after certain rounds of trial and error while circumventing unforeseeable impasses that a viable route to 2 was settled eventually [20].

Liu's approach makes use of three fragments 32, 35, and 38 (boxed in Scheme 3) to assemble the entire molecule. First, MOM protection of chlorinated tyrosine methyl ester $\mathbf{3 0}$ and then amide condensation with 5 (structure shown in Scheme 1) gave, after Boc removal, dipeptide $\mathbf{3 2}$ as the first building block. Second, vinylogous Mukaiyama aldol reaction, which is instrumental for asymmetric C-C bond formation in the preceding two syntheses (see Sections 2 and 3) [3,5], again played a key role in the preparation of $\alpha, \beta$-unsaturated carboxylic acid 35; but a somewhat differing aspect of Liu's synthesis is the use of dimethyl acetal 33, instead of previously used aldehyde 8 (see Scheme 1), as the electrophilic coupling partner. Thanks to the robustness of Kobayashi's methodology [11] and subsequent improvement by Hosokawa [14,21,22], the reaction produced 34 in $88 \%$ yield with a high level of stereoselectivity (diastereomeric ratio (d.r.) $=14: 1$ ). Alkaline hydrolysis aided by hydrogen peroxide cleaved the auxiliary portion to give 35 in $89 \%$ ee as the second necessary building 
block. Preparation of the last building block 38 entailed as the first step an environment-friendly iron-catalyzed oxidation [23] that converted 36 to 25 (structure in Scheme 2) in 76\% yield. In the meantime, trans homoallylic alcohol 37 was synthesized in $85 \%$ ee in accordance with Roush's asymmetric crotylboration method [24]. The following Mitsunobu esterification built the hindered ester linkage between 25 and 37. Since the use of protonic acids caused undesirable destannylation, Boc cleavage called for an alternative condition (TESOTf, 2,6-lutidine) to obtain 38 with a diastereomeric ratio of $14: 1$.

The endgame of Liu's synthesis commenced with pre-mixing 35 with Ghosez's reagent 39 [25], from which an acid chloride was generated as a strong acyl donor. Such in situ activated species coupled efficiently with 32 to afford 40 in $83 \%$ yield. Earlier, this tactic was employed by Wang et al. during their total synthesis of $\mathbf{1}$ in order to promote an otherwise refractory amidation reaction (the union of 49 and 54 into 55, refer to Scheme 4 and the next Section) [4]. Ester hydrolysis of 40, in conjunction with amidation with 38, gave open-chain precursor 41. In the presence of $\mathrm{Pd}\left(\mathrm{PPh}_{3}\right)_{4}$ and $\mathrm{LiCl}$ at $60{ }^{\circ} \mathrm{C}, 41$ cyclized uneventfully via Stille cross-coupling. At last, global deprotection with $p$-TsOH led to 2 in $78 \%$ yield.
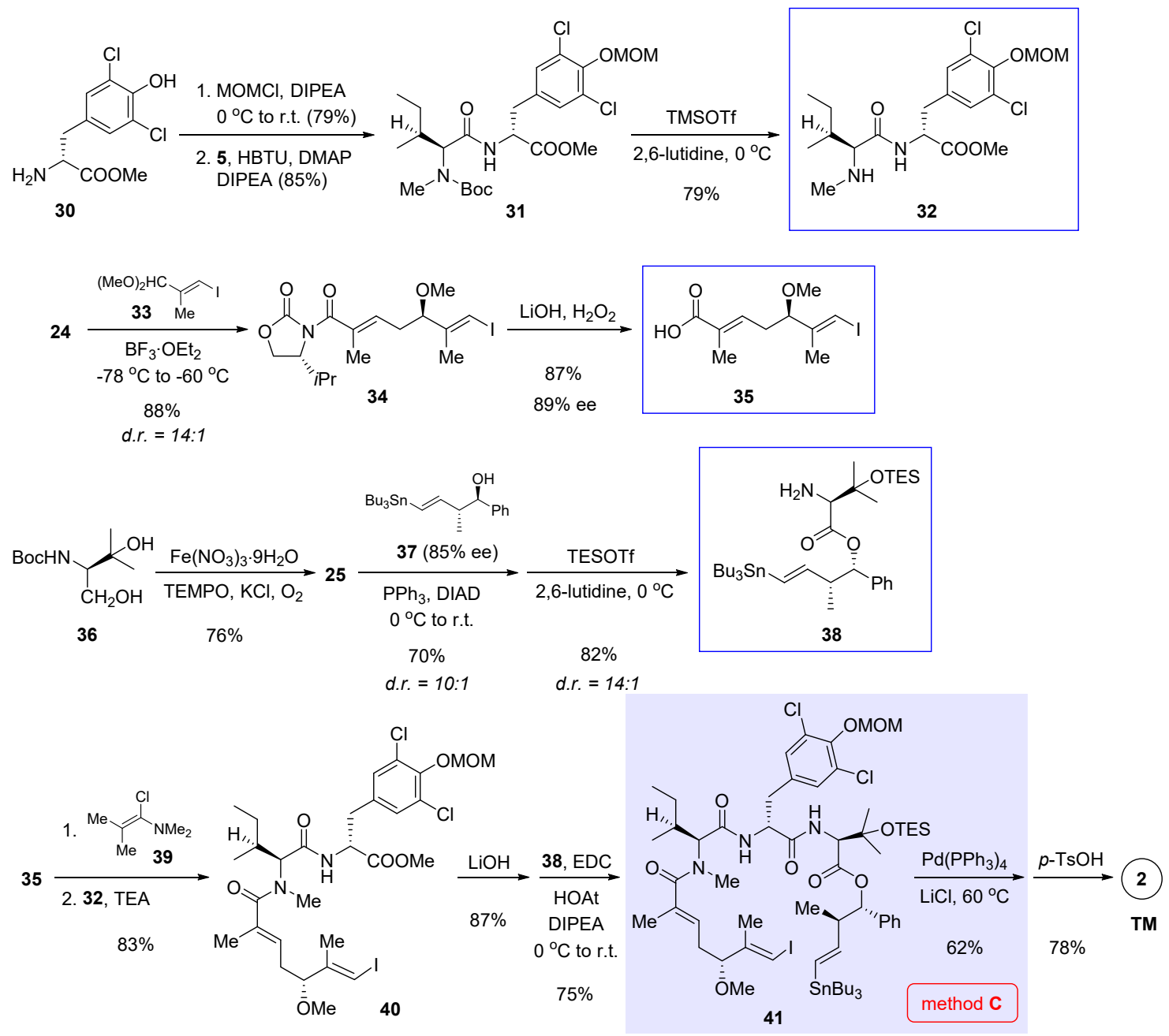

Scheme 3. Total synthesis of 2 by Liu et al. featuring macrocyclization via Stille cross-coupling (Figure 2, method C) [6]. 


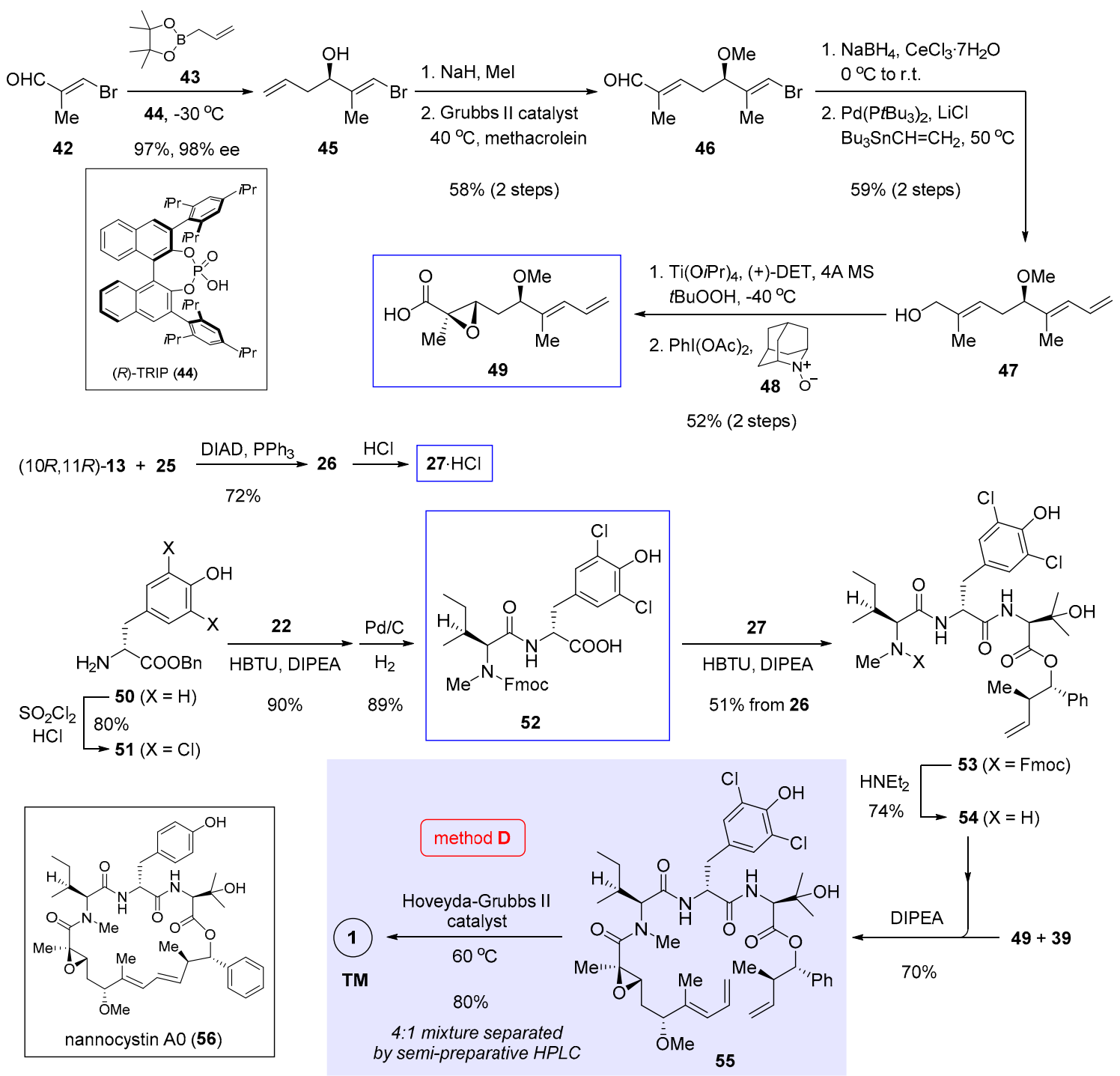

Scheme 4. Total synthesis of 1 and nannocystin A0 (56) by Wang et al. featuring macrocyclization via ring-closing alkene metathesis (Figure 2, method D) [4].

\section{Macrocyclization via Ring-Closing Alkene Metathesis}

Ring-closing alkene metathesis as a powerful ring-forming tool was applied by Wang et al. in their total synthesis of $\mathbf{1}$ [4]. This route (Figure 2, method $\mathbf{D}$ ) seeks piecemeal assemblage of the metathesis precursor 55 from three fragments 49, 27, and 52 (boxed in Scheme 4, the structure of $\mathbf{2 7}$ is shown in Scheme 2), among which $\mathbf{2 7}$ was also employed in our total synthesis [5] as has been covered in Section 3.

Inspired by Antilla's research [26], homoallylic alcohol 45 was synthesized in $97 \%$ yield and $98 \%$ ee through enantioselective allylation of (E)-3-bromomethacrolein (42) with pinacol allylboronate 43 catalyzed by axially chiral phosphoric acid (R)-TRIP (44). Methylation and alkene cross-metathesis with methacrolein extended the terminal alkene of 45 into an $\alpha, \beta$-unsaturated aldehyde. Regioselective Luche reduction of the resulting 46 followed by Stille cross-coupling with $\mathrm{Bu}_{3} \mathrm{SnCH}=\mathrm{CH}_{2}$ gave rise to allylic alcohol 47, onto which Sharpless asymmetric epoxidation installed a stereodefined epoxide. Subsequent oxidation with $\mathrm{PhI}(\mathrm{OAc})_{2}$ and $\mathrm{AZADO}(48)$ afforded the desired fragment 49. The procedure to synthesize another fragment $\mathbf{2 7}$ is almost identical to ours (refer to Scheme 2) and will not be restated. 
In the final stage, D-tyrosine benzyl ester $\mathbf{5 0}$ was converted to $\mathbf{5 1}$ via double chlorination. Succeeding the amidation of $\mathbf{5 1}$ with Fmoc protected N-methyl-L-leucine 22 (structure shown in Scheme 2), Pd/C-mediated debenzylation yielded dipeptide 52 as the third key fragment. Later, another crucial amide bond was made by coupling 52 to 27, followed by Fmoc cleavage to generate tripeptide 54. Union of the two hindered reactants 49 and $\mathbf{5 4}$ proved tricky, as a number of peptide coupling reagents failed to effect the desired transformation. Fortunately, by pre-activating 49 with Ghosez's reagent 39 (structure in Scheme 3), the intermediary participated effectively in condensation with 54 to give 55 in $70 \%$ yield. Finally, ring closure of this linear precursor in the presence of Hoveyda-Grubbs II catalyst at $60{ }^{\circ} \mathrm{C}$ brought 1 as a mixture of $4: 1$ stereoisomers. The desired natural $8 E$ isomer was isolated with semi-preparative HPLC as the major product in $80 \%$ yield. The same route also enabled access to chloro-free nannocystin A0 (56, boxed at the bottom left of Scheme 4) by coupling 50 directly to 22 without the initial double chlorination.

\section{Macrocyclization via Macrolactamization (He's Approach)}

Complementary to transition metal catalyzed reactions, macrolactamization offers a classic solution to generating the nannocystin ring. Still, shifting the cyclization site toward a transannular amide demands a full-length polyketide chain in advance. In 2017, $\mathrm{Hu}$ and $\mathrm{He}$ et al. communicated their total synthesis of $\mathbf{1}$ [7] in which the complete polyketide was prepared from three building blocks 58, 21 (structure in Scheme 2), and 64 prior to macrolactamization (Scheme 5, method E).

Taking advantage of asymmetric vinylogous Mukaiyama aldol reaction developed by Kalesse et al. [27], the authors first prepared chiral alcohol 57 bearing an $\alpha, \beta$-unsaturated aldehyde as the starting material. Methylation followed by DIBAL-H reduction (multistep reaction condition [A] at the bottom of Scheme 5) gave allylic alcohol 10 (structure in Scheme 1). Further elaborations include Sharpless asymmetric epoxidation, oxidation of the primary alcohol into a carboxylic acid, and amide coupling with 67 ([B]), thereby producing the first building bock 58 . At the same time, a combination of $\mathrm{Pd}_{2}(\mathrm{dba})_{3}$ and SPhos ligand enabled Negishi cross-coupling between iodide 59 and an arylzinc species generated in situ from $\mathbf{6 0}$. The tyrosine fragment $\mathbf{2 1}$ was then made available via TFA-mediated Boc cleavage. Preparation of the third fragment 64 started with chiral intermediate 61 [28], which underwent a sequence of PCC oxidation, modified Seyferth-Gilbert homologation using 68 [29] and TBS deprotection ([C]) to afford 62. Key to the nontrivial esterification between 62 and 63 is to mask the latter's $\beta$-hydroxyl with a TES group, otherwise $\beta$-lactone would result as a dominant by-product. Similar situation was encountered during $\mathrm{Xu}$ and Ye's synthesis (from 17 to 18 in Scheme 1), wherein the encumbering $\beta$-hydroxyl moiety necessitates temporary blocking to ensure azide reduction [3]. After that, Pd-catalyzed hydrostannylation of the terminal alkyne rendered a tributyltin-functionalized (E)-alkene in 64.

To complete the synthesis, 58 was hydrolyzed and coupled with 21, leading to 65 in $56 \%$ yield with simultaneous loss of the phenolic TBS group. After testing various catalysts for the intermolecular Stille cross-coupling between 64 and 65, an optimal ensemble of $\mathrm{Pd}_{2}(\mathrm{dba})_{3}, \mathrm{AsPh}_{3}$ [30], and DIPEA was identified to give the product 66 in $74 \%$ yield. Removing both the TES and Fmoc groups, followed by ester hydrolysis, produced a linear intermediate. The ensuing macrolactamization delivered the target molecule 1 in $40 \%$ yield over two steps ([D]). 

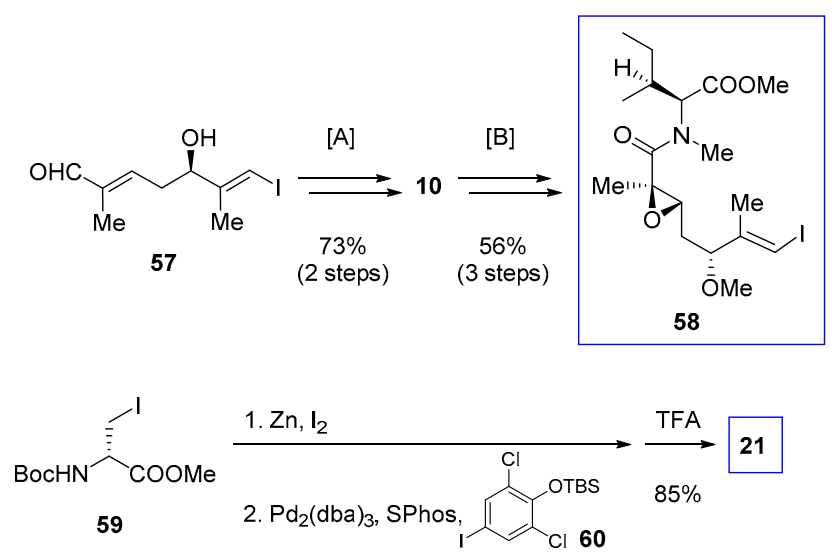

$82 \%$
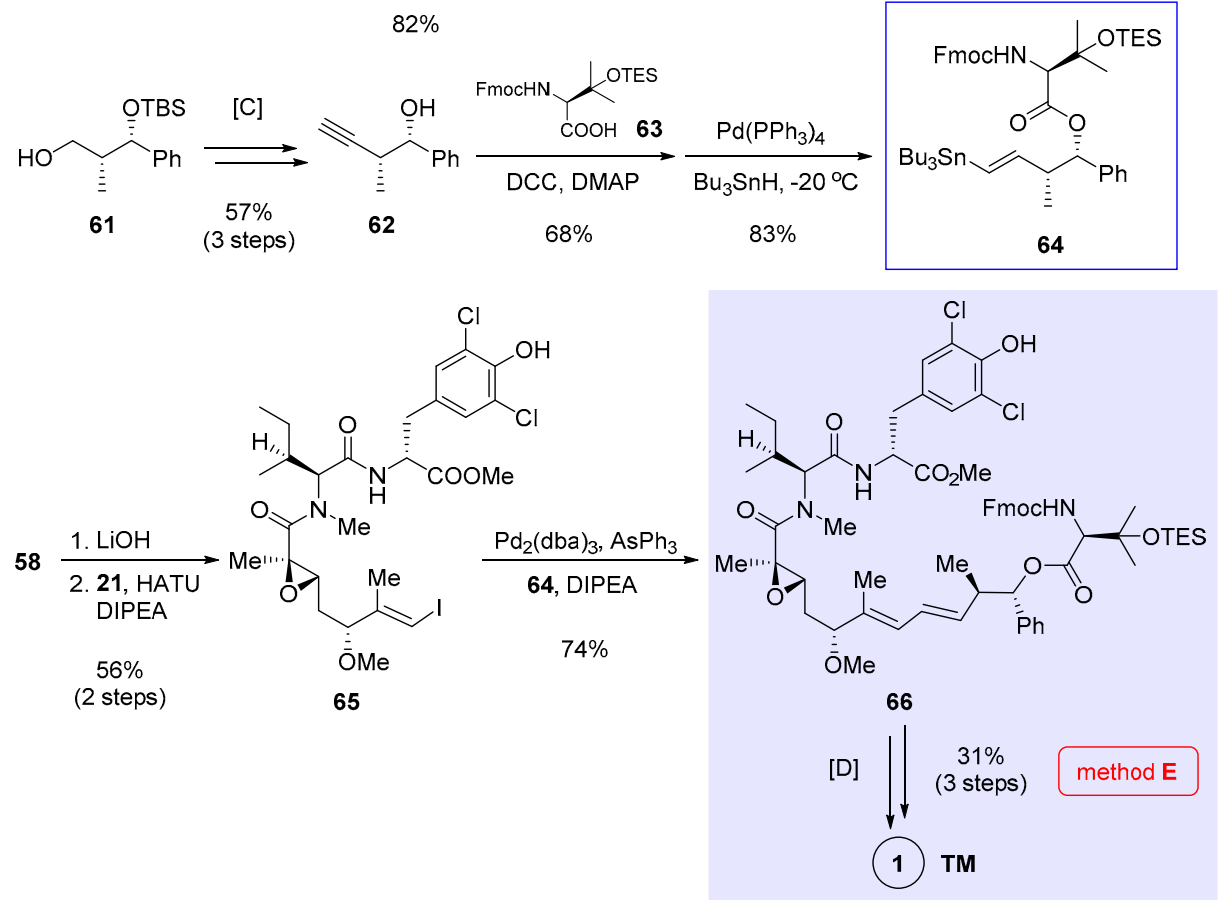

Multistep reaction conditions

[A] 1. proton sponge, $\mathrm{Me}_{3} \mathrm{O}^{+} \mathrm{BF}_{4}^{-}(78 \%)$; 2. DIBAL-H, $-20^{\circ} \mathrm{C}(93 \%)$.

[B] 1. $\mathrm{Ti}(\mathrm{OPr})_{4},(+)-\mathrm{DET}, t \mathrm{BuOOH}, 4 \mathrm{AMS}$, $-40^{\circ} \mathrm{C}(80 \%)$

2. $\mathrm{PhI}(\mathrm{OAC})_{2}$, TEMPO, $\mathrm{NaClO}_{2}, \mathrm{pH}=7$;

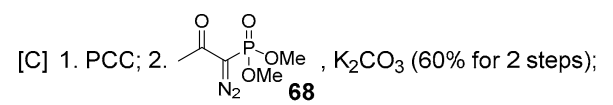
3. $\operatorname{TBAF}(95 \%)$.

[D] 1. TBAF (78\%); 2. LiOH; 3. HATU, DIPEA ( $40 \%$ for 2 steps).

3. $\underbrace{\mathrm{H}_{1} . \mathrm{MO}}_{\mathrm{NHMe} 67}, \mathrm{HATU}, \mathrm{DIPEA}(70 \%$ for 2 steps).

Scheme 5. Total synthesis of $\mathbf{1}$ by Hu and He et al. featuring macrocyclization via macrolactamization (Figure 2, method E) [7].

\section{Macrocyclization via Macrolactamization (Kalesse's Approach)}

Concurrent to Hu and He's work [7] shown in the previous section, Kalesse et al. demonstrated the viability of macrolactamization in nannocystin synthesis by utilizing a different scissile peptide bond (Figure 2, method F) [8]. Distinctive of their approach is a joint usage of asymmetric vinylogous Mukaiyama aldol condensation [13,31,32] and vinylogous Horner-Wadsworth-Emmons (HWE) reaction [33] in order to access the polyketide segment 74, to which three amino acids 63, 76, and 77 [34] (boxed in Scheme 6) are added in a stepwise fashion. The synthesis is concluded with macrolactamization and deprotection. 

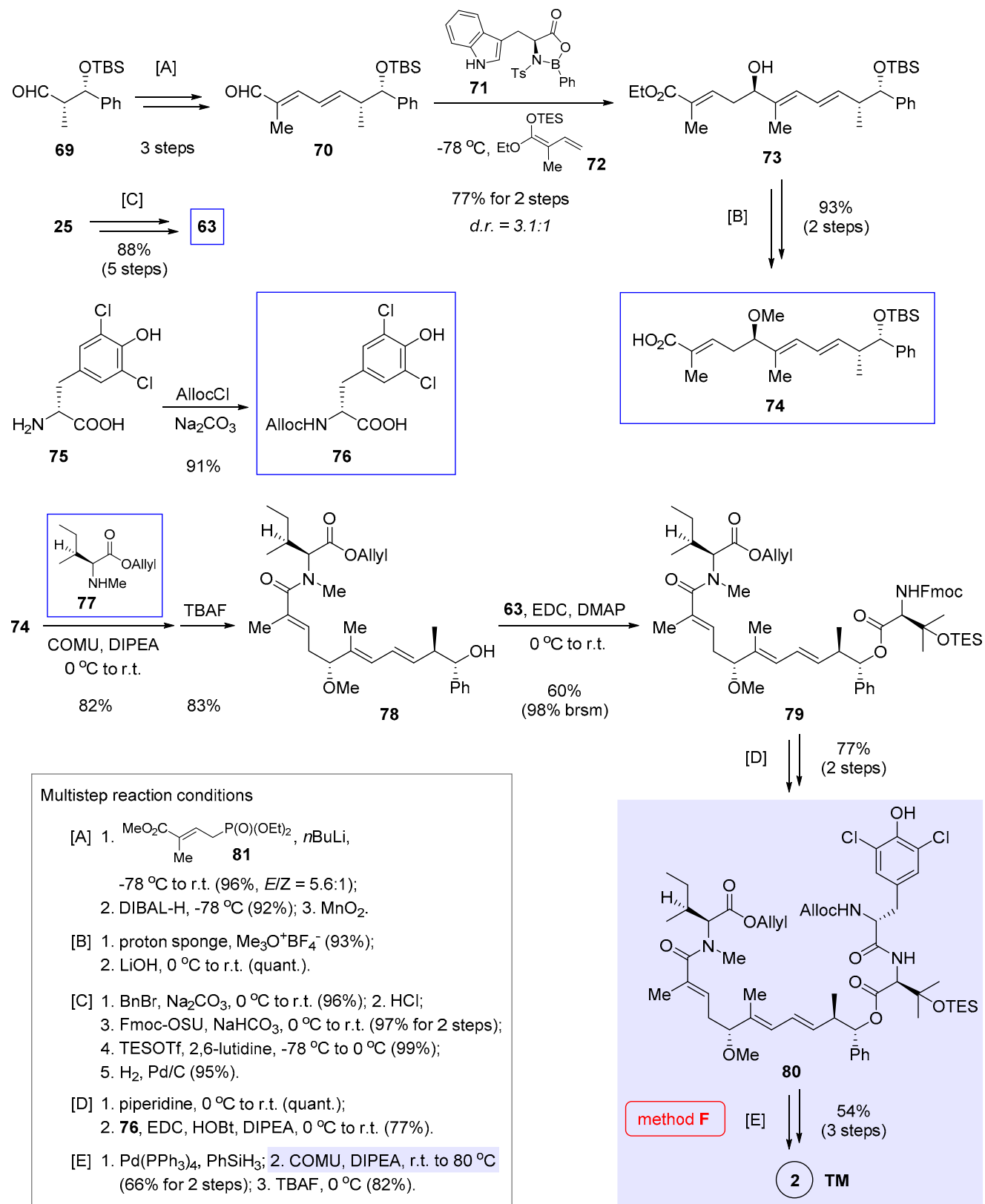

Scheme 6. Total synthesis of 2 by Kalesse et al. featuring macrocyclization via macrolactamization (Figure 2, method F) [8].

With this in mind, assembly of the polyketide portion was executed first. Thus vinylogous HWE reaction of 69 [28] with deprotonated phosphonate 81 fared well with good stereoselectivity $(E / Z=5.6: 1)$. The elongated aldehyde 70 was obtained via DIBAL-H reduction and oxidation with $\mathrm{MnO}_{2}$ (multistep reaction condition [A] at the bottom left of Scheme 6). Under the influence of chiral Lewis acid 71 developed in-house [31], vinylogous Mukaiyama aldol reaction of 70 and 72 at $-78{ }^{\circ} \mathrm{C}$ afforded 73 in a good yield ( $77 \%$ over 2 steps) but with moderate diastereoselectivity (d.r. $=3.1: 1)$. Since the two diastereomers could not be easily separated, purification was deferred to later steps. Even so, the advantage of applying chiral oxazaborolidinones such as $\mathbf{7 1}$ to this kind of transformation can still be appreciated. As noted independently by Liu et al. [20], an alternative condition $\left(\mathrm{TiCl}_{4},-78{ }^{\circ} \mathrm{C}\right)$ [11] failed to enforce coupling between $\mathbf{7 0}$ and $\mathbf{2 4}$ (structure in Scheme 2), in spite of its applicability in two earlier nannocystin syntheses (from 7 to 9 in Scheme 1, from 24 to 10 in Scheme 2) [3,5]. To continue, methylation and ester hydrolysis ([B]) generated 74 as an unstable intermediate, which was immediately 
used in the next step to avoid decomposition on storage. In parallel, protected amino acids 63 (structure in Scheme 5) and $\mathbf{7 6}$ were prepared from $\mathbf{2 5}$ (structure in Scheme 2) and $\mathbf{7 5}$ respectively

Ideally, optimal efficiency will be realized if a full-length tripeptide could add to the polyketide fragment 74, rather than introducing three discrete amino acids one at a time. Yet in reality this idea proved unworkable, even in the case of a shorter dipeptide. Echoing this result, Liu et al. were unable to modify the $\mathrm{N}$ - or C-terminus of their synthetic tripeptide intermediates when exploring a feasible route to 2 [20]. It was suspected that the tripeptide might assume a conformation unfavorable to amide condensation. Accordingly, these three amino acids $(77,63,76)$ had to be attached to the polyketide chain one by one.

In detail, the first condensation occurred between 74 and 77, for which a number of peptide coupling reagents were evaluated and only COMU gave a satisfactory yield of $82 \%$. After removing the TBS group with TBAF, the modified polyketide 78 was linked to a second amino acid 63 via esterification. The product $\mathbf{7 9}$ was isolated in a moderate yield (60\%), albeit most of unreacted $\mathbf{7 8}$ could be recovered. Fmoc deprotection and then amidation with $\mathbf{7 6}$ led to the masked linear precursor $\mathbf{8 0}$ in $77 \%$ yield ([D]). This step was found capricious, because upon scale-up the yield dropped considerably with concurring erosion of stereochemical integrity. Future endeavor to optimize these two amidation reactions shall improve the robustness of this route. After Pd-mediated reductive cleavage of the Allyl and Alloc groups of $\mathbf{8 0}$, the pivotal macrolactamization proceeded smoothly to give, after TES deprotection, nannocystin Ax (2) in 54\% yield over 3 steps ([E]).

\section{Macrocyclization via Ring-Closing Alkyne Metathesis}

Total synthesis of bioactive natural products is a prelude to SAR study [35], which helps to determine essential pharmacophores and structural redundancy so that the lead structure could evolve toward better drug-like properties. As the research objective transits from attesting synthetic accessibility to figuring out an SAR trend regarding a specific subdomain, it is sometimes imperative to design an innovative route to meet the diversity-oriented need. This point is elegantly illustrated by Fürstner's motif-oriented total synthesis of 2 and related non-natural analogues [9]. Unlike the earlier syntheses [3-8] aiming at quick access to the nannocystin framework (see Sections 2-7), this study takes inspiration from Hoepfner's docking study [2] suggesting that held by a hydrophobic pocket on the eEF1A surface, the methyl substituent of $6 E$-alkene from the nannocystin polyketide segment might play a key role in target engagement. On the other hand, negligible impact on drug-target binding would be conceived of the adjacent $5 R$-methoxy ether, since it supposedly projects away from the protein surface. Along this thought, structural permutation of $\mathbf{2}$, a close congener of $\mathbf{1}$ with comparable potency, at its $6 E$-alkene as well as the flanking $5 R$-methoxy ether (highlighted in Figure 3) would permit fine-tuning of on-target binding affinity and physicochemical properties.

\subsection{Retrosynthetic Analysis}

Retrosynthetically, 2A was decided as an advanced intermediate (Figure 3), whose C6 tributyltin unit could diversify into multiple substituents such as a methyl in $\mathbf{2}$. In turn, $\mathbf{2 A}$ would be available via Ru-catalyzed trans-hydrostannation of the corresponding propargylic alcohol 2B. Due to Fürstner's seminal works pioneering the use of $\left[C p^{*} R u\right.$-based catalysts $\left(C p^{*}=\eta^{5}-C_{5} M_{5}\right)$ [36-41], reactions of this sort now proceed with well-defined stereo- and regioselectivity, and as such have found important applications in total synthesis [42]. In the context of nannocystin synthesis, however, the authors cautioned a caveat of applying this strategy. Specifically, there resides an uncertainty of whether and/or to what extent the two weakly acidic transannular amides (red in 2B, Figure 3), due to their through-space proximity, will compromise the catalyst-steering capacity of the C5 propargylic alcohol (blue in 2B, Figure 3). Earlier studies present ample evidence that apart from hydroxyl groups, other protic functionalities such as amides and sulfonamides are likewise competent to sway this catalytic process [38,39]. Hence it is worthwhile to find out the actual magnitude of influence by these proximate amides on Ru-catalyzed trans-hydrostannation. 

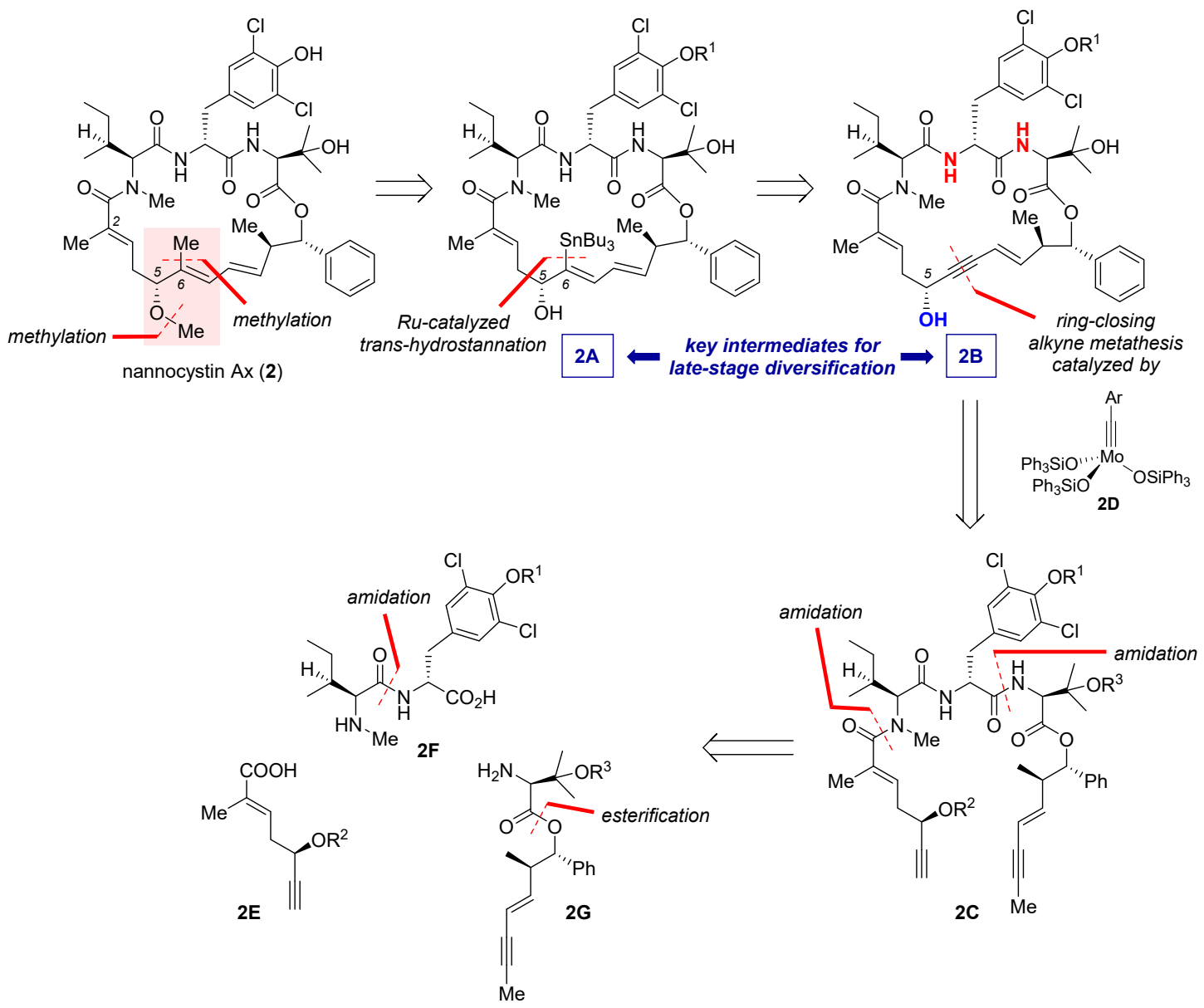

Figure 3. Retrosynthetic analysis of $\mathbf{2}$ featuring a motif-oriented late-stage diversification strategy.

Moving backward, the enyne-bearing macrocycle of $\mathbf{2 B}$ could be built via ring-closing alkyne metathesis (RCAM) [43,44] of its acyclic counterpart 2C using silyloxy-based molybdenum alkylidyne complex 2D as the catalyst (method G, Figure 2). Discovered by Fürstner et al. in 2009, 2D and its benchtop stable precursor represent a latest generation of alkyne metathesis catalysts with outstanding reactivity, functional group compatibility, and operational practicality [45-48]. Since the advent of these broadly applicable catalysts, RCAM in alliance with postmetathetic elaborations has become a privileged methodology $[49,50]$ in the total synthesis of stereodefined polyunsaturated macrocycles [51-58]. As for the present study, 2A and 2B constitute two versatile intermediates for diversification. Subsequent disconnection is straightforward in that the open-chain precursor $2 \mathrm{C}$ could stem from three distinct fragments $2 \mathrm{E}, \mathbf{2 F}$, and $\mathbf{2 G}$, among which the latter two would be assembled respectively from amidation and esterification of more basic building blocks.

\subsection{Forward Synthesis}

The first stage of the synthesis [9] as shown in Scheme 7 involves preparation of three key fragments 88, 96, and 98 (boxed in Scheme 7). To begin, Sonogashira cross-coupling merged vinyl bromide 82 and silyated alkyne 83 into enyne 84 in 63\% yield. Borrowing a new methodology developed by Buchwald et al. [59], 84 underwent $\mathrm{Cu}$-catalyzed asymmetric carbonyl addition to benzaldehyde, in which synergistic actions of a copper-hydride species and its coordinating chiral ligand $(R, R)$-Ph-BPE (85) imparted excellent optical purity $(99.5 \%$ ee) to the adduct 62 (structure shown in Scheme 5). Notwithstanding a modest yield (49\%) and diastereoselectivity (d.r. $=2.8: 1$ ), this two-step sequence compares favorably with an alternative multistep synthesis depicted partially in Scheme 5 (from 61 to 62 ). Then a second Sonogashira cross-coupling of $\mathbf{6 2}$ with iodopropyne 86, 
followed by hydroxyl-directed semireduction with Red-Al, gave rise to enyne 87 in $65 \%$ yield over 2 steps. Simultaneously, doubly protected $\beta$-hydroxyvaline 91 was supplied in 3 steps from serine derivative 89. Union of $\mathbf{8 7}$ and $\mathbf{9 1}$ occurred via esterification, with subsequent Boc removal to give $\mathbf{8 8}$ as the first key building block (multistep reaction condition [A] at the bottom of Scheme 7).

Construction of the second building block 96 started with non-stereoselective allylation of aldehyde 92. Since attempts at asymmetric allylation failed to bring about satisfactory results, enzymatic resolution was invoked to kinetically separate rac-93 into enantiomerically pure 94 and S-93. While this single-step transformation produced 94 in no more than $50 \%$ yield, the unwanted S-93 could be recycled to 94 via a stereospecific Mitsunobu reaction. In combination, the total yield of this enzymatic resolution procedure reached a satisfactory level of $90 \%$. Next, ozonolysis of the terminal alkene of 94 into an aldehyde, followed by Wittig reaction with phosphorus ylide 106 ([B]), led to 95 with excellent $E$ selectivity ( $E / Z>95: 5)$. Further elaborations ([C]), including (1) ester saponification that concomitantly deacylated the C5 alcohol, (2) TBS reprotection of the exposed chiral alcohol, (3) hydrolytic cleavage of the capping TMS group, and (4) activation of the carboxylic acid with Ghosez's reagent 39 (structure in Scheme 3), gave acid chloride 96 primed for the following amidation. Preparation of dipeptide 98, the third building block, was at the same time conducted from tyrosine ester 97 in three steps ([D]), during which Boc-protected $N$-methyl isoleucine $\mathbf{5}$ (structure in Scheme 1) was included.

With all three necessary fragments in hand, it is time to move on to the next stage, namely, to integrate them into a proper cyclization precursor. This was set out by masking the tyrosine phenol of 98 with a phenacyl group ( $\mathrm{PG}=\mathrm{CH}_{2} \mathrm{C}(\mathrm{O}) \mathrm{Ph}$ ). Though counterintuitive at first glance, the choice of this unorthodox moiety turned out crucial in downstream elaborations. If an acetyl group was used instead, the synthesis could advance without complication until the very step of Cu-mediated C6-methylation (from 103a to 104a, Scheme 7), where it was prone to transannular rearrangement with consequent elimination of the acetoxyl moiety to render an allene by-product.

Continuing the synthesis, ester hydrolysis of the phenacyl-protected dipeptide and amidation with 88 created tripeptide derivative 99 ([E]). To bring in the missing piece $\mathbf{9 6 , 9 9}$ was treated with large excess of TBSOTf and 2,6-lutidine so that Boc deprotection occurred with simultaneous $N$-silylation. Aqueous work-up with TBAF liberated the tripeptide $\mathrm{N}$-terminus, which coupled efficiently to acid chloride 96 and gave the linear compound 100 ([F]). In the presence of molybdenum alkylidyne catalyst 108 (corresponding to 2D in Figure 3), RCAM succeeded in forging the 21-membered ring in 66\% yield. This result once again exemplifies the robustness of silanolate-ligated molybdenum catalysts in building heavily functionalized macrocycles. Removal of the TBS group then afforded $\mathbf{1 0 2}$ carrying the requisite propargylic alcohol for directed hydrostannation. On the premise of slowly introducing $\mathrm{Bu}_{3} \mathrm{SnH}$ into the reaction mixture, the Ru-catalyzed addition proceeded cleanly to deliver $\mathbf{1 0 3}$ as the only detectable regio- and stereoisomer in $80 \%$ yield.

On account of such extraordinary selectivity irrespective of two potentially disruptive amides, the authors determined the X-ray single crystal structure of 102 (Figure 4). Obviously, the propargylic alcohol subunit (highlighted red) is situated within a relatively open hemisphere of the macrocycle vis-à-vis the northern side comprising a densely substituted tripeptide. This unbalanced steric environment has dual consequences: on the one hand, it grants access to the bulky [RuCp*]-based catalyst, allowing it to approach the enyne substructure from below so as to be precisely guided by the $\mathrm{C} 5$ alcohol for desirable selectivity; on the other, buried inside the congesting tripeptide hemisphere, the two protic amides become less likely to extend their influence on the Ru catalyst. Overall, the solid-state structure of $\mathbf{1 0 2}$ provides a concrete rationale for the observed reaction outcome. Of further note is the efficacy of sequential RCAM and directed trans-hydrostannation in constructing macrocycles with a stereodefined $E$-alkene. While RCM of dienes has been widely applied to preparing various-sized rings, a remaining challenge is to control the $E / Z$-selectivity of the nascent alkene, not to mention its indiscriminating reactivity toward alkenes and alkynes [43]. 

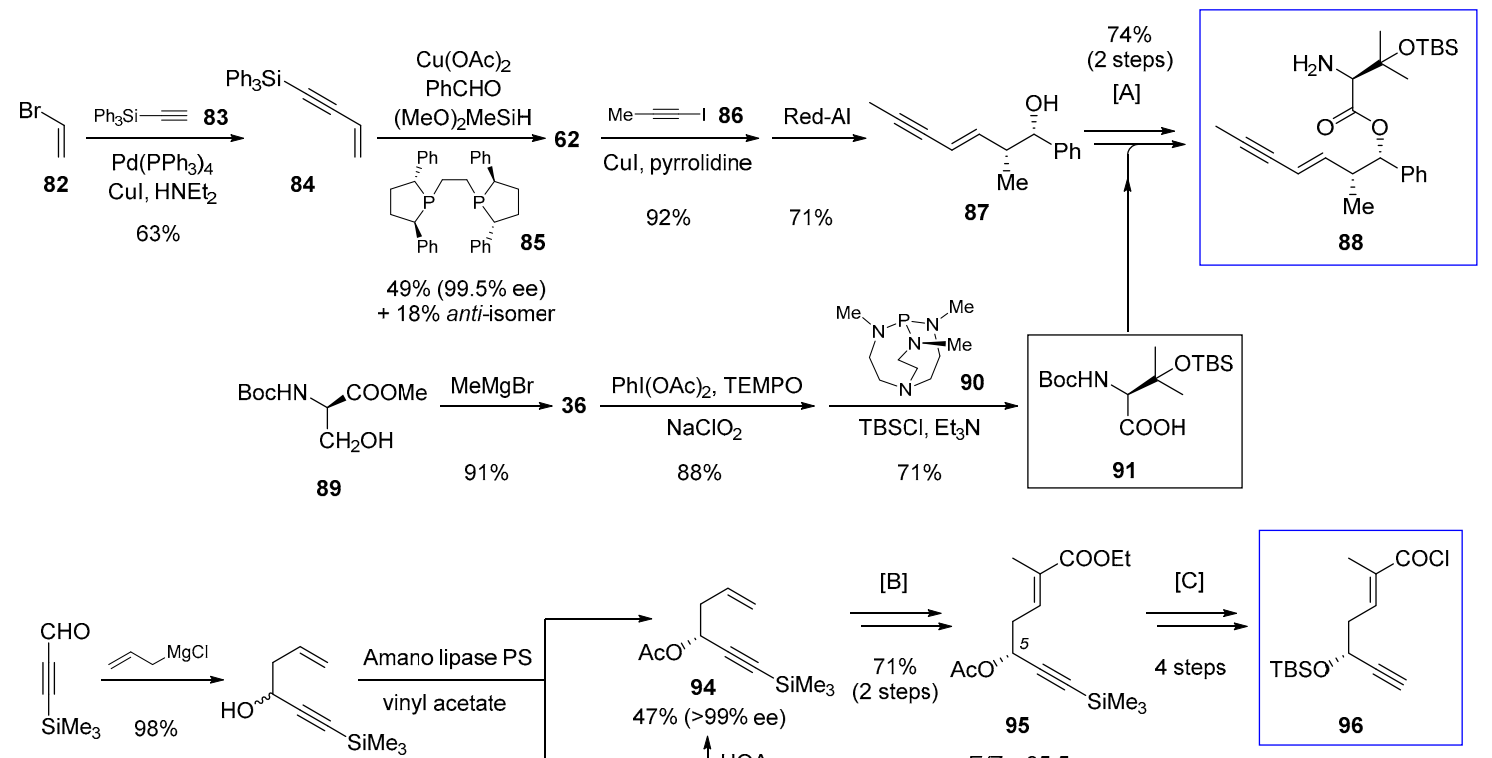

92 rac-93

$$
\begin{aligned}
& \rightarrow \text { S-93 } \begin{array}{l}
\text { HOAC } \\
\text { DIAD, } \mathrm{PPh}_{3}
\end{array} \\
& 47 \% \quad 91 \% \\
& \text { (>99\% ee) }
\end{aligned}
$$
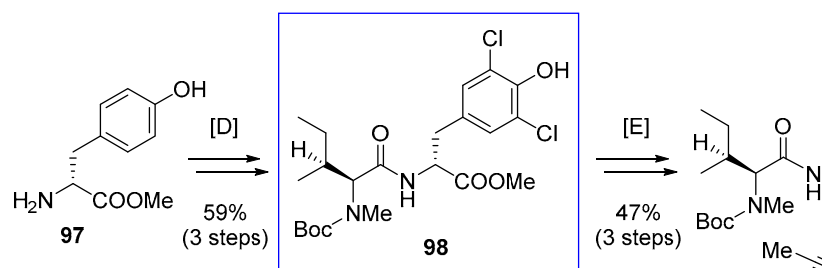<smiles>Cc1cc(Cl)c([18O])c(Cl)c1</smiles>
(3 steps) $\mathrm{Boc}^{-\mathrm{NMe}^{\mathrm{H}}}$
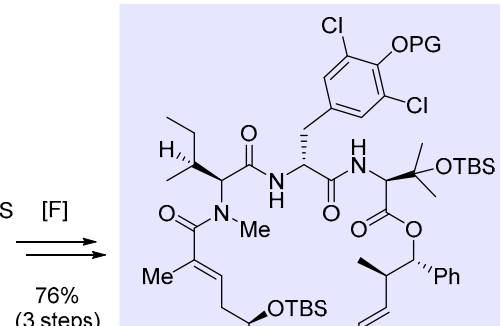<smiles>C#C/C=C/C(C)CC</smiles>

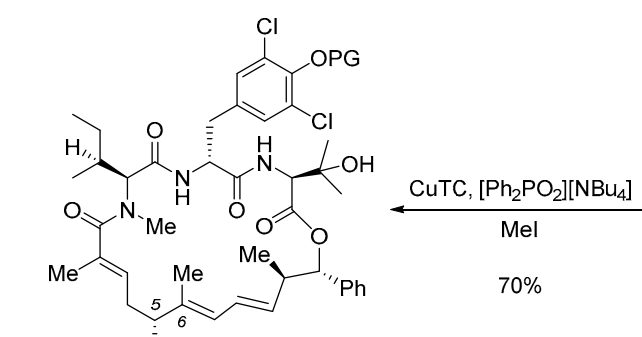

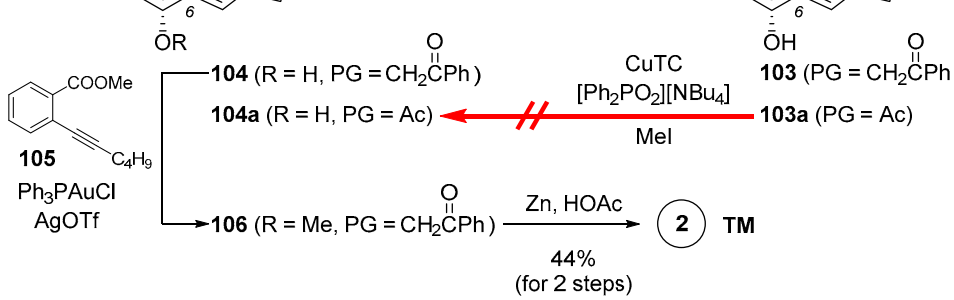

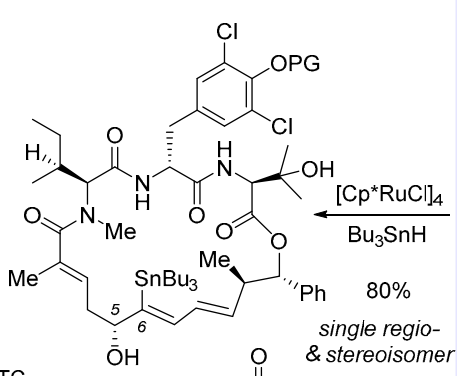
single regiosomer

$$
\begin{aligned}
& \text { HF, pyridine }-101(R=T B S) \\
& \text { (71\%) } \\
& \begin{array}{c}
\longrightarrow 102(\mathrm{R}=\mathrm{H}) \\
\stackrel{\mathrm{O}}{\mathrm{II}} \\
\left(\mathrm{PG}=\mathrm{CH}_{2} \stackrel{\mathrm{C}}{\mathrm{Ph}}\right)
\end{array}
\end{aligned}
$$




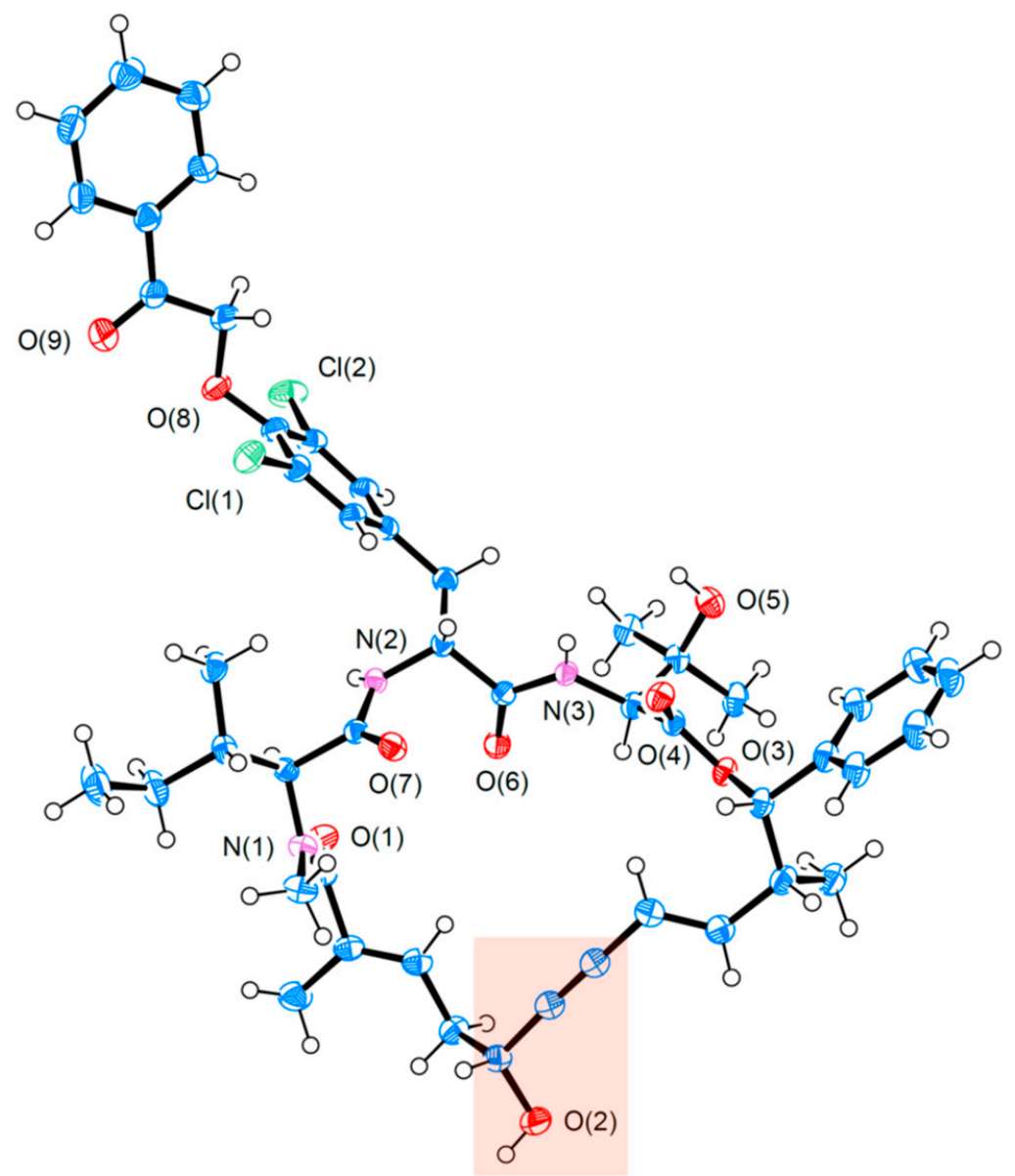

Figure 4. X-ray single crystal structure of the key intermediate 102 during Fürstner's total synthesis of 2 [9], with its propargylic alcohol highlighted. (ORTEP representation is drawn at $50 \%$ probability for thermal ellipsoids.).

Toward completion of the synthesis, 103 was subjected to Cu-promoted C6-methylation [60], which produced trisubstituted alkene 104 with intact $E$ geometry. Surprisingly, the penultimate step of methylating the $\mathrm{C} 5$ alcohol appeared quite challenging, as several commonly used conditions (e.g., $\mathrm{MeI} / \mathrm{Ag}_{2} \mathrm{O}$, $\left[\mathrm{Me}_{3} \mathrm{O}\right] \mathrm{BF}_{4}, \mathrm{MeOTs} / \mathrm{K}_{2} \mathrm{CO}_{3}$ ) failed to produce 106 with decent reliability. Considerable experimentation led to the discovery that base-free gold-catalyzed cyclization [61] of 105 released a methyl cation, which was in no time trapped by the C5 alcohol of 104 to give the methyl ether 105 . In the end, reductive cleavage of the phenacyl group with Zn dust afforded 2 in $44 \%$ yield over 2 steps. From the late-stage intermediates 102 and 103, further diversification provided an array of novel nannocystins 109a-109j (Figure 5) for a focused SAR study. 


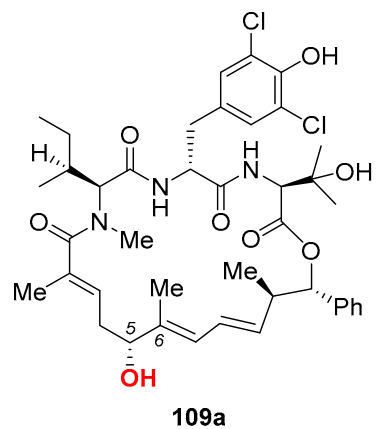

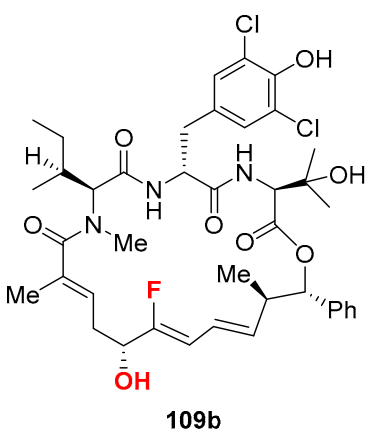

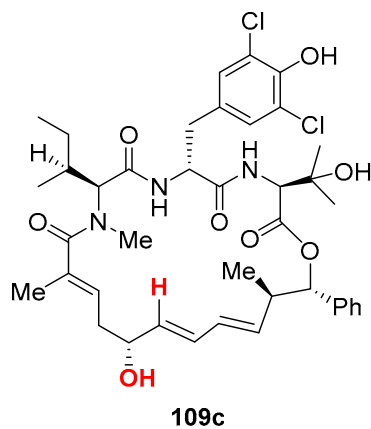

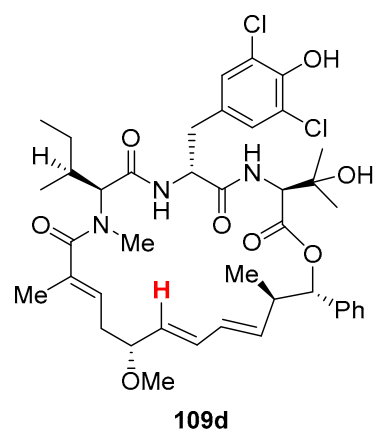

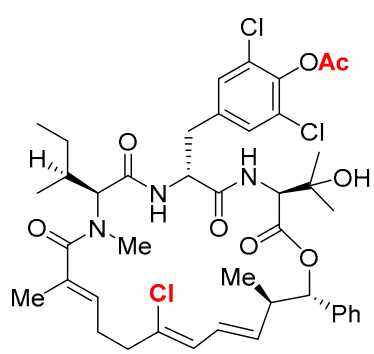

ӧH

$109 \mathrm{e}$

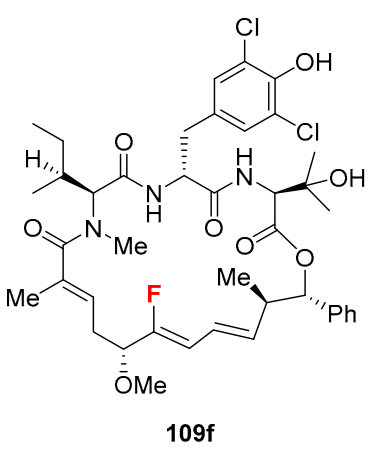

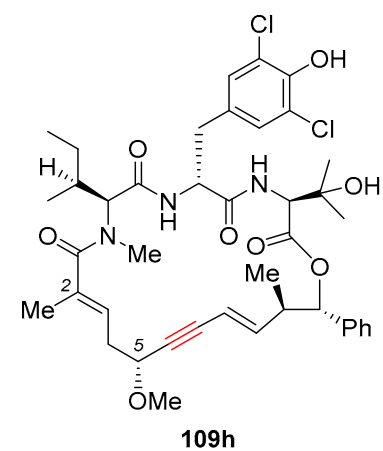

$109 \mathrm{~h}$

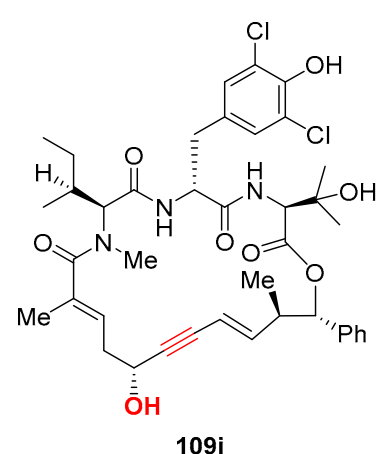

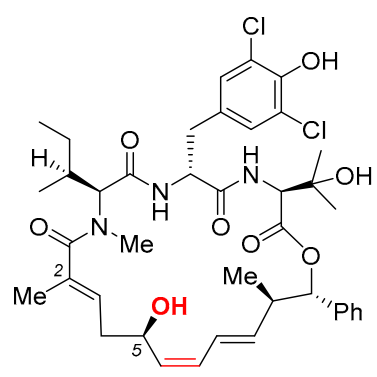

$109 \mathrm{j}$

\begin{tabular}{|c|c|c|}
\hline Starting material & Reaction conditions (yield) & Product \\
\hline 104 & $\mathrm{Zn}, \mathrm{HOAc}(78 \%)$ & $109 a$ \\
\hline 103 & $\begin{array}{l}\text { 1. } \mathrm{AgOP}(\mathrm{O}) \mathrm{Ph}_{2}, \mathrm{~F}-\mathrm{TEDA}-\mathrm{PF}_{6}(54 \%) \text {; } \\
\text { 2. } \mathrm{Zn}, \mathrm{HOAc}(87 \%) \text {. }\end{array}$ & $109 b$ \\
\hline 103 & $\begin{array}{l}\text { 1. } \mathrm{CuTC},\left[\mathrm{Ph}_{2} \mathrm{PO}_{2}\right]\left[\mathrm{NBu}_{4}\right](86 \%) \text {; } \\
\text { 2. } \mathrm{Zn}, \operatorname{HOAc}(75 \%) \text {. }\end{array}$ & $109 c$ \\
\hline 103 & $\begin{array}{l}\text { 1. } \mathrm{CuTC},\left[\mathrm{Ph}_{2} \mathrm{PO}_{2}\right]\left[\mathrm{NBu}_{4}\right] \\
\text { 2. } 106, \mathrm{Ph}_{3} \mathrm{PAuCl}, \mathrm{AgOTf} \\
\text { 3. } \mathrm{Zn}, \mathrm{HOAc}(37 \% \text { for } 3 \text { steps }) \text {. }\end{array}$ & $109 d$ \\
\hline $103 a$ & $\mathrm{CuCl}_{2}$, lutidine (82\%) & $109 e$ \\
\hline 103 & $\begin{array}{l}\text { 1. } \mathrm{AgOP}(\mathrm{O}) \mathrm{Ph}_{2}, \mathrm{~F}-\mathrm{TEDA}-\mathrm{PF}_{6} \\
\text { 2. } \mathrm{MeOTs}, \mathrm{K}_{2} \mathrm{CO}_{3} \\
\text { 3. } \mathrm{Zn}, \mathrm{HOAc}(34 \%(109 \mathrm{f})+28 \%(109 \mathrm{~g}) \\
\text { for } 3 \text { steps })\end{array}$ & $109 f, 109 g$ \\
\hline 102 & $\begin{array}{l}\text { 1. MeOTs, } \mathrm{K}_{2} \mathrm{CO}_{3} \text {; } \\
\text { 2. } \mathrm{Zn}, \mathrm{HOAc} \text { ( } 45 \% \text { for } 2 \text { steps). }\end{array}$ & $109 \mathrm{~h}$ \\
\hline 102 & $\mathrm{Zn}, \mathrm{HOAc}(80 \%)$ & $109 i$ \\
\hline $109 i$ & $\mathrm{Zn}(\mathrm{Cu} / \mathrm{Ag})(62 \%)$ & 109j \\
\hline
\end{tabular}

Figure 5. Novel nannocystins 109a-109j prepared during Fürstner's motif-oriented total synthesis of 2 [9]. The inset table catalogs their preparation conditions.

\section{Conclusions}

All roads lead to Rome. This old adage is true of natural product total synthesis. With a fixed target in mind and an ever expanding toolkit of useful reactions at hand, there can be more than one route to conquer it. Nevertheless, all such roads are different, which is likewise true of total synthesis, as demonstrated by the seven nannocystin total syntheses. Though each approach is uniquely creative, certain approaches turn out more convenient for structural variation. Based on a robust Heck macrocyclization [5], we have been able to conduct systematic SAR study [15-17]. Meanwhile, having succeeded in a macrolactamization strategy [7], He et al. later opted for our 
Heck macrocyclization approach in a subsequent SAR study [18]. This transition reflects the value of synthetic practicality in diversity-driven synthesis. Yet with this strategy, it is still cumbersome to modify the polyketide C5-C9 segment, which according to docking calculation is situated at the forefront of target engagement. Fortunately, Fürstner et al. came up with the motif oriented strategy to tackle this challenge. RCAM in coalition with Ru-catalyzed trans-hydrostannation keyed facile access to a library of novel analogues, thereby enriching our knowledge on the SAR of nannocystins. In this case, complementarity in synthetic strategies translates smoothly into that for structural diversification. Both methods, the target-oriented and the motif-oriented, are therefore indispensable for gaining a comprehensive SAR trend, the very road map guiding natural product based drug discovery.

Funding: This research was funded by the National Natural Science Foundation of China (grant number 21772101) and the Natural Science Foundation of Tianjin City (grant number 17JCYBJC28400).

Conflicts of Interest: The author declares no conflict of interest.

\section{References}

1. Hoffmann, H.; Kogler, H.; Heyse, W.; Matter, H.; Caspers, M.; Schummer, D.; Klemke-Jahn, C.; Bauer, A.; Penarier, G.; Debussche, L.; et al. Discovery, Structure Elucidation, and Biological Characterization of Nannocystin A, a Macrocyclic Myxobacterial Metabolite with Potent Antiproliferative Properties. Angew. Chem. Int. Ed. 2015, 54, 10145-10148. [CrossRef] [PubMed]

2. Krastel, P.; Roggo, S.; Schirle, M.; Ross, N.T.; Perruccio, F.; Aspesi, P.; Aust, T.; Buntin, K.; Estoppey, D.; Liechty, B.; et al. Nannocystin A: An Elongation Factor 1 Inhibitor from Myxobacteria with Differential Anti-Cancer Properties. Angew. Chem. Int. Ed. 2015, 54, 10149-10154. [CrossRef] [PubMed]

3. Liao, L.; Zhou, J.; Xu, Z.; Ye, T. Concise Total Synthesis of Nannocystin A. Angew. Chem. Int. Ed. 2016, 55, 13263-13266. [CrossRef] [PubMed]

4. Huang, J.; Wang, Z. Total Syntheses of Nannocystins A and A0, Two Elongation Factor 1 Inhibitors. Org. Lett. 2016, 18, 4702-4705. [CrossRef] [PubMed]

5. Yang, Z.; Xu, X.; Yang, C.-H.; Tian, Y.; Chen, X.; Lian, L.; Pan, W.; Su, X.; Zhang, W.; Chen, Y. Total Synthesis of Nannocystin A. Org. Lett. 2016, 18, 5768-5770. [CrossRef] [PubMed]

6. Zhang, Y.; Liu, R.; Liu, B. Total synthesis of nannocystin Ax. Chem. Commun. 2017, 53, 5549-5552. [CrossRef]

7. Liu, Q.; Hu, P.; He, Y. Asymmetric Total Synthesis of Nannocystin A. J. Org. Chem. 2017, 82, 9217-9222. [CrossRef]

8. Poock, C.; Kalesse, M. Total Synthesis of Nannocystin Ax. Org. Lett. 2017, 19, 4536-4539. [CrossRef]

9. Meng, Z.; Souillart, L.; Monks, B.; Huwyler, N.; Herrmann, J.; Müller, R.; Fürstner, A. A “Motif-Oriented” Total Synthesis of Nannocystin Ax. Preparation and Biological Assessment of Analogues. J. Org. Chem. 2017, 83, 6977-6994. [CrossRef]

10. Wang, Z. The Chemical Syntheses of Nannocystins. Synthesis 2019, 51, 2252-2260. [CrossRef]

11. Shirokawa, S.-I.; Kamiyama, M.; Nakamura, T.; Okada, M.; Nakazaki, A.; Hosokawa, S.; Kobayashi, S. Remote Asymmetric Induction with Vinylketene Silyl N,O-Acetal. J. Am. Chem. Soc. 2004, 126, 13604-13605. [CrossRef] [PubMed]

12. Casiraghi, G.; Battistini, L.; Curti, C.; Rassu, G.; Zanardi, F. The Vinylogous Aldol and Related Addition Reactions: Ten Years of Progress. Chem. Rev. 2011, 111, 3076-3154. [CrossRef] [PubMed]

13. Kalesse, M.; Cordes, M.; Symkenberg, G.; Lu, H.-H. The vinylogous Mukaiyama aldol reaction (VMAR) in natural product synthesis. Nat. Prod. Rep. 2014, 31, 563-594. [CrossRef] [PubMed]

14. Hosokawa, S. Remote Asymmetric Induction Reactions using a E,E-Vinylketene Silyl N,O-Acetal and the Wide Range Stereocontrol Strategy for the Synthesis of Polypropionates. Acc. Chem. Res. 2018, 51, 1301-1314. [CrossRef]

15. Tian, Y.; Xu, X.; Ding, Y.; Hao, X.; Bai, Y.; Tang, Y.; Zhang, X.; Li, Q.; Yang, Z.; Zhang, W.; et al. Synthesis and biological evaluation of nannocystin analogues toward understanding the binding role of the (2R,3S)-Epoxide in nannocystin A. Eur. J. Med. Chem. 2018, 150, 626-632. [CrossRef]

16. Tian, Y.; Ding, Y.; Xu, X.; Bai, Y.; Tang, Y.; Hao, X.; Zhang, W.; Chen, Y. Total synthesis and biological evaluation of nannocystin analogues modified at the polyketide phenyl moiety. Tetrahedron Lett. 2018, 59, 3206-3209. [CrossRef] 
17. Tian, Y.; Wang, J.; Liu, W.; Yuan, X.; Tang, Y.; Li, J.; Chen, Y.; Zhang, W. Stereodivergent total synthesis of Br-nannocystins underpinning the polyketide $(10 R, 11 S)$ configuration as a key determinant of potency. J. Mol. Struct. 2019, 1181, 568-578. [CrossRef]

18. Liu, Q.; Yang, X.; Ji, J.; Zhang, S.-L.; He, Y. Novel nannocystin A analogues as anticancer therapeutics: Synthesis, biological evaluations and structure-activity relationship studies. Eur. J. Med. Chem. 2019, 170, 99-111. [CrossRef]

19. Sierra, M.A.; de la Torre, M.C. Dead Ends and Detours: Direct Ways to Successful Total Synthesis; Wiley-VCH: Weinheim, Germany, 2004.

20. Liu, R.; Xia, M.; Zhang, Y.; Fu, S.; Liu, B. The journey of total synthesis toward nannocystin Ax. Tetrahedron 2019, 75, 1781-1794. [CrossRef]

21. Tsukada, H.; Mukaeda, Y.; Hosokawa, S. syn-Selective Kobayashi Aldol Reaction Using Acetals. Org. Lett. 2013, 15, 678-681. [CrossRef]

22. Sagawa, N.; Sato, H.; Hosokawa, S. Remote Asymmetric Induction Using Acetate-Type Vinylketene Silyl N,O-Acetals. Org. Lett. 2016, 19, 198-201. [CrossRef] [PubMed]

23. Jiang, X.; Zhang, J.; Ma, S. Iron Catalysis for Room-Temperature Aerobic Oxidation of Alcohols to Carboxylic Acids. J. Am. Chem. Soc. 2016, 138, 8344-8347. [CrossRef] [PubMed]

24. Chen, M.; Roush, W.R. Enantioconvergent Hydroboration of a Racemic Allene: Enantioselective Synthesis of (E)- $\delta$-Stannyl-anti-homoallylic Alcohols via Aldehyde Crotylboration. J. Am. Chem. Soc. 2011, 133, 5744-5747. [CrossRef] [PubMed]

25. Ghosez, L. $\alpha$-Chloroenamines: New Reagents for Organic Synthesis. Angew. Chem. Int. Ed. 1972, 11, $852-853$. [CrossRef]

26. Jain, P.; Antilla, J.C. Chiral Brønsted Acid-Catalyzed Allylboration of Aldehydes. J. Am. Chem. Soc. 2010, 132, 11884-11886. [CrossRef]

27. Gieseler, M.T.; Kalesse, M. Asymmetric Vinylogous Mukaiyama Aldol Reaction of Aldehyde-Derived Dienolates. Org. Lett. 2011, 13, 2430-2432. [CrossRef]

28. Schläger, N.; Kirschning, A. Substrate-controlled stereoselectivity in the Yamamoto aldol reaction. Org. Biomol. Chem. 2012, 10, 7721-7729. [CrossRef]

29. Müller, S.; Liepold, B.; Roth, G.J.; Bestmann, H.J. An Improved One-pot Procedure for the Synthesis of Alkynes from Aldehydes. Synlett 1996, 521-522. [CrossRef]

30. Farina, V.; Krishnan, B. Large rate accelerations in the Stille reaction with tri-2-furylphosphine and triphenylarsine as palladium ligands: Mechanistic and synthetic implications. J. Am. Chem. Soc. 1991, 113, 9585-9595. [CrossRef]

31. Simsek, S.; Horzella, M.; Kalesse, M. Oxazaborolidinone-Promoted Vinylogous Mukaiyama Aldol Reactions. Org. Lett. 2007, 9, 5637-5639. [CrossRef]

32. Kalesse, M.; Brodmann, T.; Lorenz, M.; Schäckel, R.; Simsek, S. Highly Stereoselective Aldol Reactions in the Total Syntheses of Complex Natural Products. Synlett 2009, 174-192. [CrossRef]

33. Gerstmann, L.; Kalesse, M. Total Synthesis of Aetheramide A. Chem. Eur. J. 2016, 22, 11210-11212. [CrossRef] [PubMed]

34. Reddy, K.V.; Sunitha, M.; Chakunta, R.G. Stereoselective Synthesis of Southern Fragment of Hantupeptin-A. Acta Chim. Slov. 2016, 63, 344-350. [CrossRef]

35. Itoh, H.; Inoue, M. Comprehensive Structure-Activity Relationship Studies of Macrocyclic Natural Products Enabled by Their Total Syntheses. Chem. Rev. 2019, 119, 10002-10031. [CrossRef]

36. Radkowski, K.; Sundararaju, B.; Fürstner, A. A Functional-Group-Tolerant Catalytic trans Hydrogenation of Alkynes. Angew. Chem. Int. Ed. 2013, 52, 355-360. [CrossRef]

37. Sundararaju, B.; Fürstner, A. A trans-Selective Hydroboration of Internal Alkynes. Angew. Chem. Int. Ed. 2013, 52, 14050-14054. [CrossRef]

38. Rummelt, S.M.; Fürstner, A. Ruthenium-Catalyzed trans-Selective Hydrostannation of Alkynes. Angew. Chem. Int. Ed. 2014, 53, 3626-3630. [CrossRef]

39. Rummelt, S.M.; Radkowski, K.; Rosca, D.-A.; Fürstner, A. Interligand Interactions Dictate the Regioselectivity of trans-Hydrometalations and Related Reactions Catalyzed by [C $\left.{ }^{*} \mathrm{RuCl}\right]$. Hydrogen Bonding to a Chloride Ligand as a Steering Principle in Catalysis. J. Am. Chem. Soc. 2015, 137, 5506-5519. [CrossRef]

40. Roşca, D.-A.; Radkowski, K.; Wolf, L.M.; Wagh, M.; Goddard, R.; Thiel, W.; Fürstner, A. Ruthenium-Catalyzed Alkynetrans-Hydrometalation: Mechanistic Insights and Preparative Implications. J. Am. Chem. Soc. 2017, 139, 2443-2455. [CrossRef] 
41. Fürstner, A. trans-Hydrogenation, gem-Hydrogenation, and trans-Hydrometalation of Alkynes: An Interim Report on an Unorthodox Reactivity Paradigm. J. Am. Chem. Soc. 2019, 141, 11-24. [CrossRef]

42. Frihed, T.G.; Fürstner, A. Progress in the trans-reduction and trans-hydrometalation of internal alkynes. Applications to natural product synthesis. Bull. Chem. Soc. Jpn. 2016, 89, 135-160. [CrossRef]

43. Fürstner, A. Alkyne Metathesis on the Rise. Angew. Chem. Int. Ed. 2013, 52, 2794-2819. [CrossRef] [PubMed]

44. Fürstner, A. Chapter 4 Alkyne metathesis in organic synthesis. In Modern Alkyne Chemistry: Catalytic and Atom-Economic Transformations; Trost, B.M., Li, C.-J., Eds.; Wiley-VCH: Weinheim, Germany, 2015; pp. 69-111.

45. Bindl, M.; Stade, R.; Heilmann, E.K.; Picot, A.; Goddard, R.; Fürstner, A. Molybdenum Nitride Complexes with $\mathrm{Ph}_{3} \mathrm{SiO}$ Ligands Are Exceedingly Practical and Tolerant Precatalysts for Alkyne Metathesis and Efficient Nitrogen Transfer Agents. J. Am. Chem. Soc. 2009, 131, 9468-9470. [CrossRef] [PubMed]

46. Heppekausen, J.; Stade, R.; Goddard, R.; Fürstner, A. Practical New Silyloxy-Based Alkyne Metathesis Catalysts with Optimized Activity and Selectivity Profiles. J. Am. Chem. Soc. 2010, 132, 11045-11057. [CrossRef] [PubMed]

47. Heppekausen, J.; Stade, R.; Kondoh, A.; Seidel, G.; Goddard, R.; Fürstner, A. Optimized Synthesis, Structural Investigations, Ligand Tuning and Synthetic Evaluation of Silyloxy-Based Alkyne Metathesis Catalysts. Chem. Eur. J. 2012, 18, 10281-10299. [CrossRef]

48. Hillenbrand, J.; Leutzsch, M.; Fürstner, A. Molybdenum Alkylidyne Complexes with Tripodal Silanolate Ligands: The Next Generation of Alkyne Metathesis Catalysts. Angew. Chem. Int. Ed. 2019, 58, 15690-15696. [CrossRef]

49. Fürstner, A. Teaching Metathesis "Simple" Stereochemistry. Science 2013, 341, 1229713. [CrossRef]

50. Fürstner, A. Catalysis for Total Synthesis: A Personal Account. Angew. Chem. Int. Ed. 2014, 53, 8587-8598. [CrossRef]

51. Willwacher, J.; Fürstner, A. Catalysis-Based Total Synthesis of Putative Mandelalide, A. Angew. Chem. Int. Ed. 2014, 53, 4217-4221. [CrossRef]

52. Ungeheuer, F.; Fürstner, A. Concise Total Synthesis of Ivorenolide B. Chem. Eur. J. 2015, 21, 11387-11392. [CrossRef]

53. Ahlers, A.; de Haro, T.; Gabor, B.; Fürstner, A. Concise Total Synthesis of Enigmazole A. Angew. Chem. Int. Ed. 2016, 55, 1406-1411. [CrossRef] [PubMed]

54. Kwon, Y.; Schulthoff, S.; Dao, Q.M.; Wirtz, C.; Fürstner, A. Total Synthesis of Disciformycin A and B: Unusually Exigent Targets of Biological Significance. Chem. Eur. J. 2018, 24, 109-114. [CrossRef] [PubMed]

55. Mata, G.; Wölfl, B.; Fürstner, A. Synthesis and Molecular Editing of Callyspongiolide, Part 1: The Alkyne Metathesis/trans-Reduction Strategy. Chem. Eur. J. 2019, 25, 246-254. [CrossRef] [PubMed]

56. Wölfl, B.; Mata, G.; Fürstner, A. Total Synthesis of Callyspongiolide, Part 2: The Ynoate Metathesis/cis-Reduction Strategy. Chem. Eur. J. 2019, 25, 255-259. [CrossRef] [PubMed]

57. Karier, P.; Ungeheuer, F.; Ahlers, A.; Anderl, F.; Wille, C.; Fürstner, A. Metathesis at an Implausible Site: A Formal Total Synthesis of Rhizoxin, D. Angew. Chem. Int. Ed. 2019, 58, 248-253. [CrossRef]

58. Meng, Z.; Fürstner, A. Total Synthesis of (-)-Sinulariadiolide. A Transannular Approach. J. Am. Chem. Soc. 2019, 141, 805-809. [CrossRef]

59. Yang, Y.; Perry, I.B.; Lu, G.; Liu, P.; Buchwald, S.L. Copper-catalyzed asymmetric addition of olefin-derived nucleophiles to ketones. Science 2016, 353, 144-150. [CrossRef]

60. Huwyler, N.; Radkowski, K.; Rummelt, S.M.; Fürstner, A. Two Enabling Strategies for the Stereoselective Conversion of Internal Alkynes into Trisubstituted Alkenes. Chem. Eur. J. 2017, 23, 12412-12419. [CrossRef]

61. Preindl, J.; Jouvin, K.; Laurich, D.; Seidel, G.; Fürstner, A. Gold- or Silver-Catalyzed Syntheses of Pyrones and Pyridine Derivatives: Mechanistic and Synthetic Aspects. Chem. Eur. J. 2016, 22, 237-247. [CrossRef]

Publisher's Note: MDPI stays neutral with regard to jurisdictional claims in published maps and institutional affiliations. 